\author{
Talib Z. Farge \\ Electronmechanical \\ Engineering Department, University \\ of Technology, Baghdad, Iraq \\ drtalebzf@yahoo.com
}

\section{Sahar R. Al-Sakini \\ Electronmechanical Engineering \\ Department, University of \\ Technology, Baghdad, Iraq \\ dr_saharalsakini@yahoo.com}

\author{
Aseel A. Ismael \\ Electronmechanical Engineering \\ Department, University of \\ Technology, Baghdad, Iraq \\ aseelahmed8423@yahoo.com
}

Received on: 16/08/2018

Accepted on: 13/12/2018

Published online: 25/01/2019

\title{
Examining the Impact of Different Thermosyphon Diameters and Working Fluids on Their Performance
}

\begin{abstract}
This work was designed to examine the effect of various thermosyphon diameters and working fluids on the thermosyphon performance. A thermosyphon made from copper tubes with three different external diameters 7, 13 and $22 \mathrm{~mm}$ with thickness of $1 \mathrm{~mm}$ is used in this work. The length of evaporator and condenser were 120 and $300 \mathrm{~mm}$ respectively. Working fluids were water, acetone and Freon R11 working fluids are tested. The obtained results have shown that the temperature gradient was decreased when increasing the thermosyphon diameter. Also, the results showed that the Merit for water had the highest value than the other working fluid at the operating range of temperature. The results were shown the heat dissipation by the thermosyphon increased when increasing the thermosyphon diameter for all working fluids. Also the heat dissipation from the thermosyphon with working fluid of water had a highest value of heat dissipation than the others working fluids. The percentage decreased in the temperature gradient by using thermosyphon with diameter of $22 \mathrm{~mm}$ for water, acetone and Freon R11 were $73.53 \%, 68,53 \%$ and $52.35 \%$ respectively compared with that without using thermosyphon.
\end{abstract}

Keywords- Two Phase Closed Thermosyphon, Merit number, Temperature gradient.

How to cite this article T.Z. Farge S.R. Al-Sakini and A.A. Ismael, "Examining the Impact of Different Thermosyphon Diameters and Working Fluids on its Performance," Engineering and Technology Journal, Vol. 37, Part A, No. 1, pp. 46-51, 2019.

\section{Introduction}

The closed thermosyphon of two phase is a simple but efficacious heat transfer apparatus. It is a vertically oriented towards heat pipe with a pool at the bed. The thermosyphon consists three sections [1] as shown in Figure. 1. Heat is supplied at the bottom evaporator section where the liquid pool exists and it is utilized to convert the working fluid into a vapor. The vapor rises towards the top condenser section. In the condenser section, the vapor concentrates and relinquishes its implicit heat. The gravity effect reverses the condensate back to the evaporator. The thermosyphons are being used in many applications as very efficient, precision with almost very inexpensive. Several common applications of heat pipe includes turbine blade cooling, waste heat recovery, heat exchanger fins, electrical motor cooling, transformer cooling, nuclear reactor cooling, cryogenic cool down apparatus, cooling of internal combustion engines etc [2] .

Previous study [3] has designed, fabricated and tested a diminutive heat tube of $5 \mathrm{~mm}$ diameter and $150 \mathrm{~mm}$ length with a thermal ability of 10 W. Experiments was carried out with and without working fluid for different thermal burdens to examine the execution of heat pipe. The working fluids selected for the test were water, methanol and acetone. However, the whole heat transfer coefficient of the miniature heat pipe for the acetone being the working fluid was found to be the maximum.

Another work [4] has examined the effect of different parameters to thermal ability of two

Phase thermosyphon using three different diameters which were 6.7, 9.54 and $12 \mathrm{~mm}$. Each tube has $1000 \mathrm{~mm}$ length and consisted of evaporation section with $300 \mathrm{~mm}$ long, adiabatic section with $200 \mathrm{~mm}$ long, and condensation section with $500 \mathrm{~mm}$ long. Heating the evaporator was supplied by electric heater while the condenser was cooled by water in tube heat exchanger. The working fluids used were water, ethanol, methanol, and acetone with filling ratio between $30 \%$ to $90 \%$. This work has observed that the best heat transfer capability of working fluids was water, while the lowest heat transfer capability was acetone.

Lab examination of heat transfers of internally finned thermosyphon loaded with water or acetone was conducted by recent work [5] at filling percentage of 20,50 , and $80 \%$ for the two working fluids and power levels of 50 and 275 
W. The results have found that the better performance was

The object of the present investigation is to investigate the effect of different diameters and working fluid on the heat dissipation by the thermosyphon.

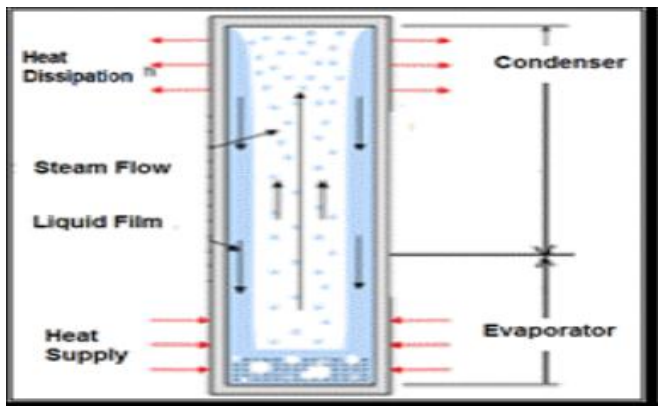

Figure 1: schematic of close two phase thermosyphon

at fill ratio of $50 \%$, and the internal fins providing condenser to additional area to improve performance of thermosyphon. However, further recent work [6] has invented and built an experimental test rig to examine thermal efficiency of two-phase, closed thermosyphon using water, ethanol, and ethylene glycol as working fluids under various operating conditions such as tilt angles, heat inputs and flow rates of cooling water. The efficiency of the thermosyphon of each working fluid at different operating conditions was found to vary from $30 \%$ to $95 \%$. These results have shown that the water was the best at low heat inputs while ethanol was the best working fluid but at high heat inputs. Also, this work has found that tilt angle and heat inputs have clear effects on the thermosyphon efficiency.

\section{Experimental Work}

The current study was designed to experimentally examine the effects of tube diameters and working fluids on the thermosyphon performance to a best heat pipe diameter and working fluids with filing ratio of $50 \%$.

To test thermal capacity of a two phase closed thermosyphon, an experiment has been conducted and the schematic of this experimental test is shown in the Figure 2. The experimental model descriptions of two phase closed thermosyphon are tabulated in Table 1. The test rig consists of oil reservoir, heater, four sealed copper tubes as thermosyphon where each of them has different diameters as shown in Figure 3 and data logger measuring instruments with five thermocouples type K. Each of the three thermosyphon under this study has length of the evaporator section of $120 \mathrm{~mm}$ and condenser section of $300 \mathrm{~mm}$ but with different external diameters of 7, 13 and $22 \mathrm{~mm}$ while the wall thickness was of $1 \mathrm{~mm}$. The evaporator part was heated by the heating transformer oil via external heater with power $750 \mathrm{~W}$, while condenser part was cooled by air naturally. Five thermocouples (K Type) were insulted on the wall of thermosyphon to measure the temperature at evaporator and condenser sections as shown in figure 3 . Thermocouples have been connected the data logger. Prior filling the pipe, it has been thoroughly cleaned up to take off any grease or oil from inside surface. A vacuum pump was used to eliminate any non-condensable gases from the thermosyphon. Finally, the pipe was loaded with the working fluids at filling ratio of $50 \%$ and then evacuated by using a vacuum pump to pressure near -760 $\mathrm{mm} \mathrm{Hg}$.

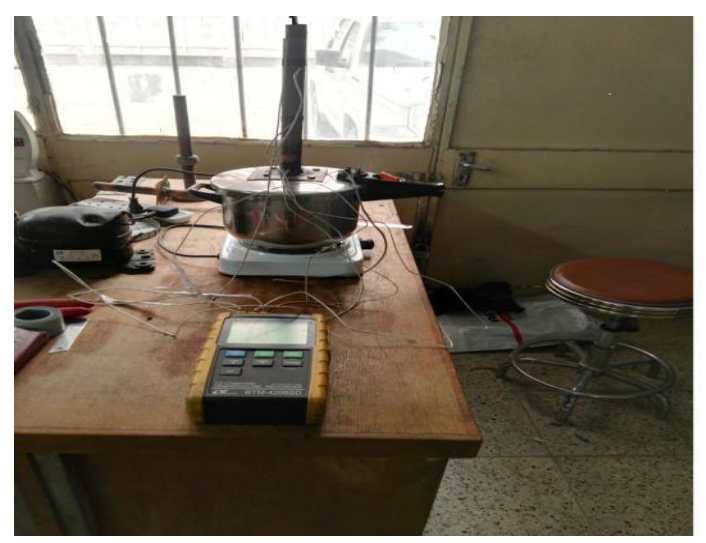

(a): experimental test

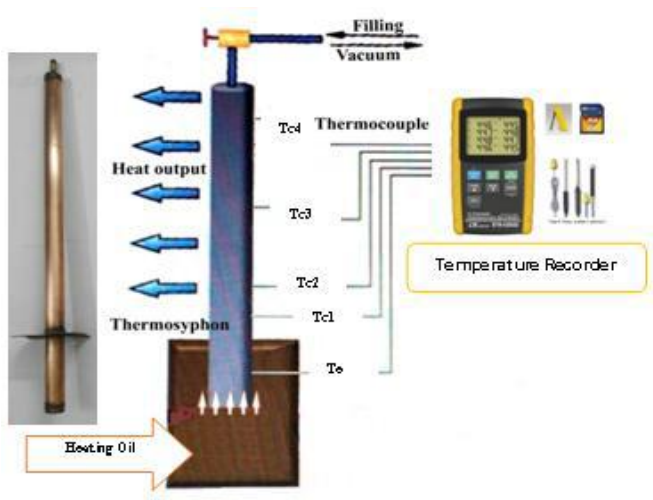

(b): Sketch of thermosyphon Figure 2: Experimental test 


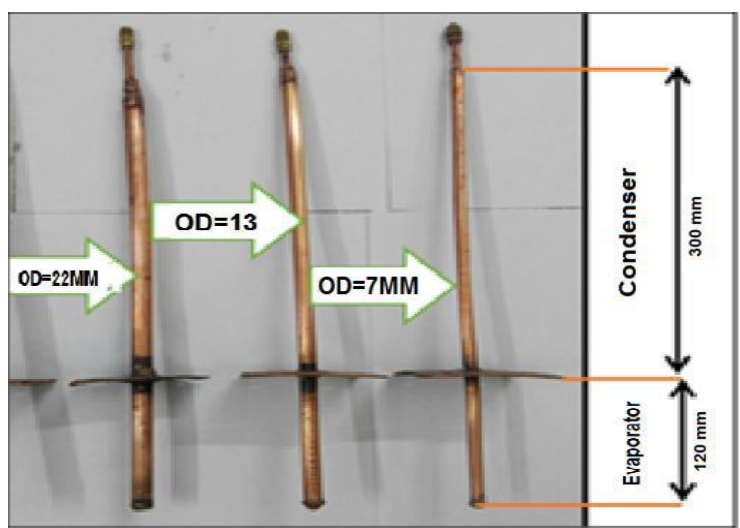

Figure 3: Thermosyphon with three different diameters

Table 1: Experimental Model Description.

\begin{tabular}{rrr}
\hline \hline Diameter & External tube & $\mathrm{mm} 7$ \\
& diameter 1 & $13 \mathrm{~mm}$ \\
& External tube & $22 \mathrm{~mm}$ \\
& diameter 2 & $120 \mathrm{~mm}$ \\
& External tube & $300 \mathrm{~mm}$ \\
& diameter 3 & $1 \mathrm{~mm}$ \\
& Evaporator & \\
& length \\
& Condenser \\
& length \\
& Thickness of \\
& tubes & \\
Working fluid & Water, acetone, \\
& Freon R11 \\
Filling ratio & $50 \%$ \\
Thermocouples & K Type \\
\hline
\end{tabular}

\section{Calculations}

The thermal performance tests of thermosyphon were performed, where heat transfer of Q oil for thermosyphon can be calculated as, [7];

$\mathrm{Q}_{\text {oil }}=\mathrm{m} * \mathrm{c}_{\mathrm{p}} * \Delta \mathrm{T}$

Where: $m, C_{p}$ represent the mass and specific heat capacity of oil, and temperature difference.

Oil specific heat can be calculated by following equation [8].

$\mathrm{C}_{\mathrm{p}}=807.163+3.58 * \mathrm{~T}$

T: oil temperature $(\mathrm{k})$

The Merit number is obtained by:

Merit number $=\left(\mathrm{h}_{\mathrm{fg}} * \mathrm{k}^{3} * \rho^{2} / \mu\right)^{.25}(\mathrm{Watt} / \mathrm{m})$

Where:

$\mathrm{h}_{\mathrm{fg}}=$ specific enthalpy of evaporation $(\mathrm{J} / \mathrm{kg})$

$\mathrm{k}_{1}$ represents thermal conductivity of the liquid phase of the working fluid (W/m.k)

$\rho_{1}=$ density of the liquid phase of the

working fluid $\left(\mathrm{kg} / \mathrm{m}^{3}\right)$

$\mu_{1}=$ dynamic viscosity of liquid phase of the working fluid $(\mathrm{kg} / \mathrm{m} . \mathrm{s})$

Where the dimensionless temperature was equal to:

Dimensionless temperature $=\frac{T-T_{a m b}}{T_{\max }-T_{a m b}}$

$$
(\nabla T)=\frac{\Delta T}{\Delta t}
$$

Where Temperature dimensionless is equal to

$\nabla T \%=\frac{\nabla T_{\text {without thermosyphon }}-\nabla T_{\text {with thermosyphon }}}{\nabla T_{\text {without thermosyphon }}} * 100 \%$ (6)

\section{Results and discussion}

Figures 4,5 and 6 show the relation between the temperature distribution along the thermosyphon wall and the time for different working fluid (water, acetone, Freon R11) and for different external diameters. The figures show that the curves were wobbling at Tc1 and the wobbling increased towards the top region of the condensation section.

This is because the saturated steam flow upwards from the center of the heat pipe, met the top wall and caused an increase in the wall temperature. In addition, the thickness of liquid film near the wall was lower at the upper side and increases as the liquid flew downwards. Lower liquid thickness at the upper side can causes a decrease in liquid film thermal resistance. Therefore, the convection heat transfer from this side to the lateral wall was higher than those of lower regions of the condenser. This can be the reason for higher observed wall's temperatures at the upper side of the condenser. These results are supported by those obtained by previous work [14].

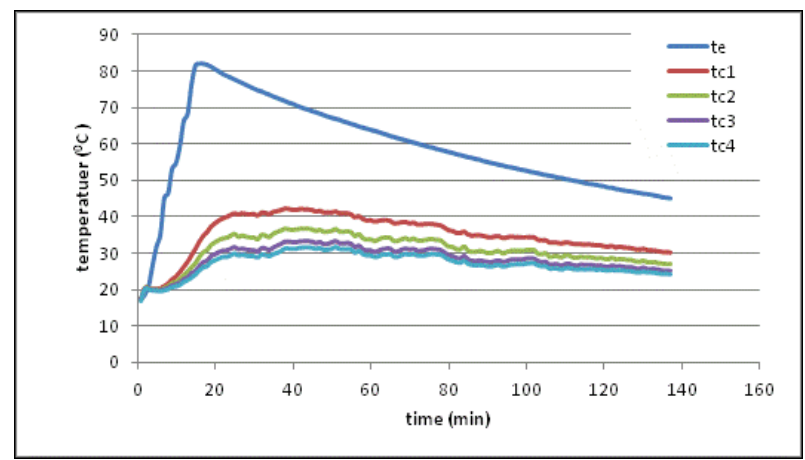

(a): outer diameter $=22 \mathrm{~mm}$

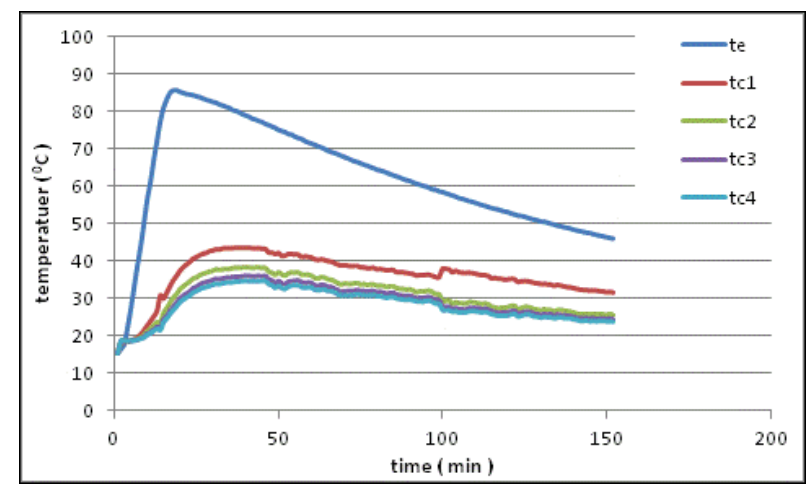

(b): outer diameter $=13 \mathrm{~mm}$

Temperature gradient 


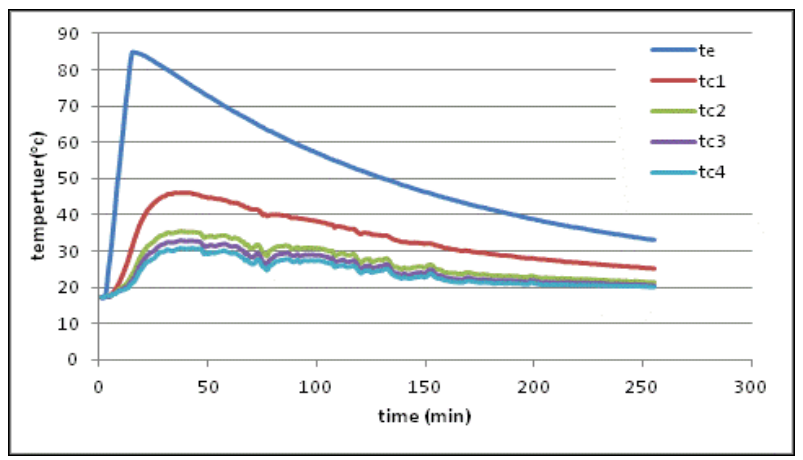

(c): outer diameter $=7 \mathrm{mmFigure} \mathrm{4:}$ Temperature distribution of distilled water with time for different outer heat pipe diameters, a. 22mm; b. 13mm; c. $7 \mathrm{~mm}$.

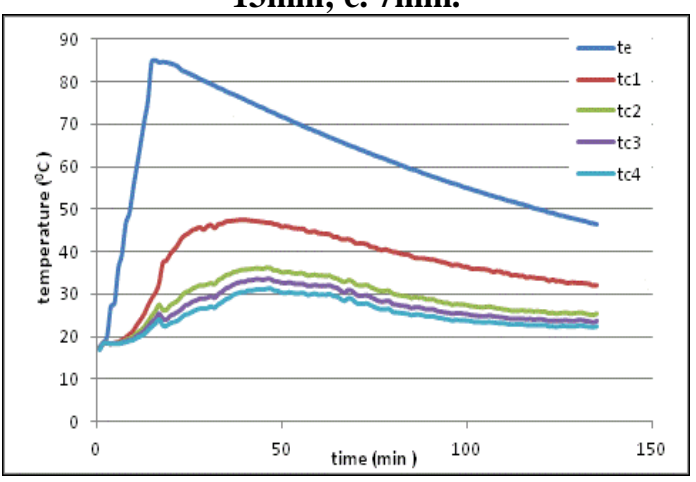

(a): outer diameter $=22 \mathrm{~mm}$

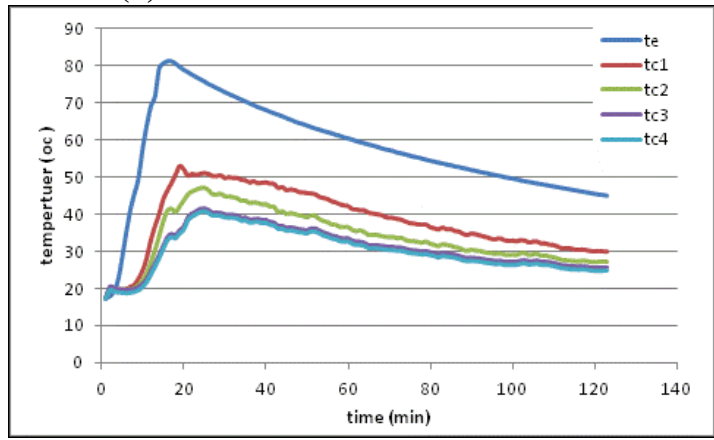

(b): outer diameter $=13 \mathrm{~mm}$

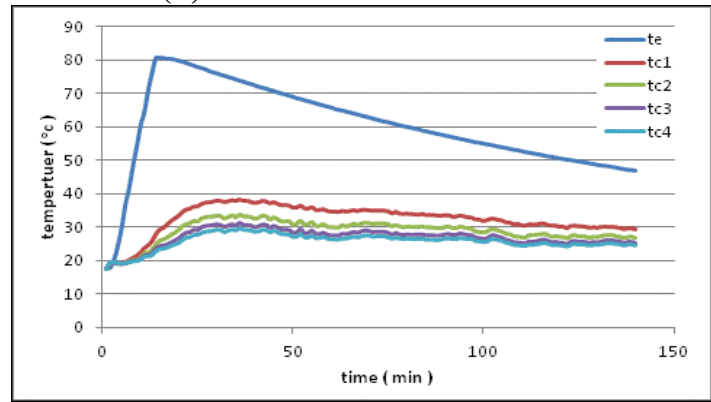

(c): outer diameter $=22 \mathrm{~mm}$

Figure 5: Temperature distributionof acetone with time for different outerheat pipe diameters, $a$.

$22 \mathrm{~mm}$; b. $13 \mathrm{~mm}$; c. $7 \mathrm{~mm}$.

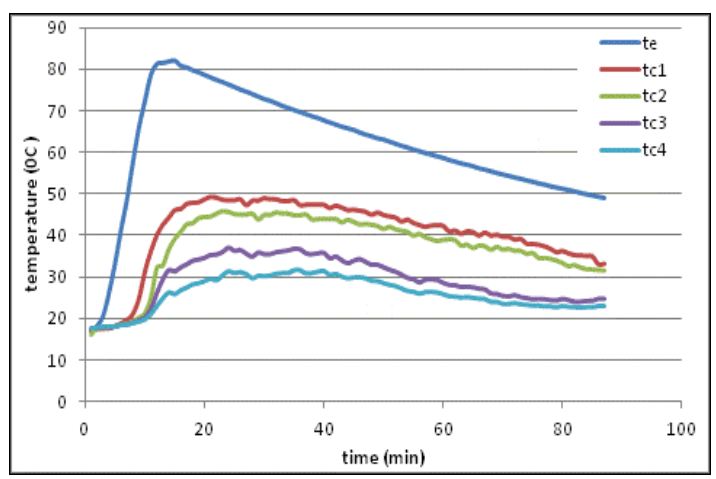

(a): outer diameter $=22 \mathrm{~mm}$

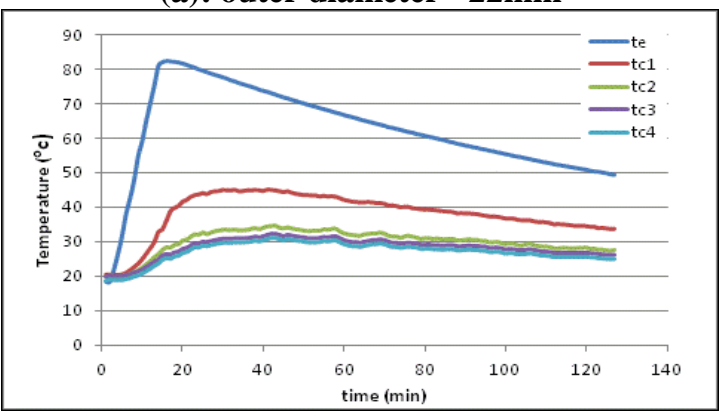

(b): outer diameter $=13 \mathrm{~mm}$

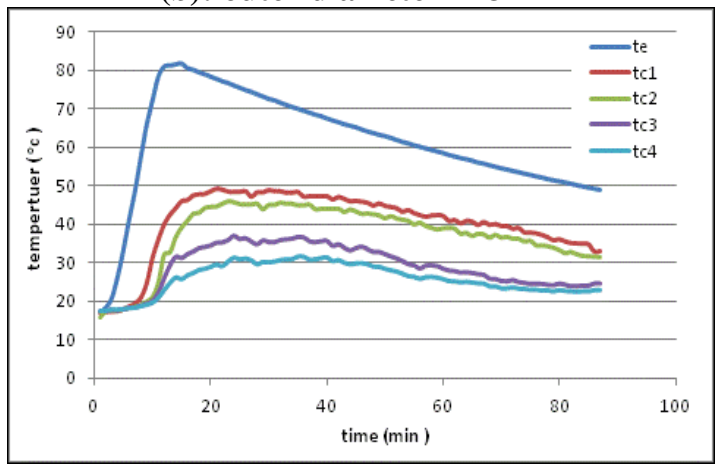

(c): outer diameter $=7 \mathrm{~mm}$

Figure 6: Temperature distribution of Freon R11 with time for different outer heat pipe diameters, a. $22 \mathrm{~mm}$; b. $13 \mathrm{~mm}$; c. $7 \mathrm{~mm}$.

Figure 7 shows the merit number of the three different working fluids (water, acetone and Freon R11) in case of the heating pipe diameter of $22 \mathrm{~mm}$ and for the temperature range of operation from the ambient temperature $(18-21$ $\left.{ }^{\circ} \mathrm{C}\right)$ up to almost $\quad 80{ }^{\circ} \mathrm{C}$. The Merit number indicates to the properties of working fluid with its capacity of the maximum heat transmission. So the Figure shows that water used as working fluid has a higher Merit number than the those of other fluids for the arrange of operating temperature from 20 to $80{ }^{\circ} \mathrm{C}$. So, the water has better thermal properties as latent heat, boiling temperature and surface tension than those of the other fluids. So, in the case of heat pipe with water as working fluid, has absorbed higher value of heat by the evaporator and condenser heat dissipation by the condenser due to better thermal properties of water than the others.

Figure 8 .Shows the heat absorbed by the oil with different thermosyphon diameters and different 
working fluids at temperature of $80{ }^{\circ} \mathrm{C}$. It seems that the heat dissipation of the working fluid of water and the higher diameter of the heat pipes have given a better thermal performance due to better thermal properties of water working fluid firstly and secondly due the larger surface area of the larger thermosyphon diameter.

Figure 9. Shows the dimensionless temperature of the oil of the different working fluids (Water, acetone and FreonR11) with thermosyphon diameter of $22 \mathrm{~mm}$ and without heat pipe.

The figure shows the temperature gradient was decreased with using water as working fluid more than others (acetone and Freon R11) due to higher thermal properties of the water.

Figure 10 shows the percentage was decreased in the temperature gradient of the different working fluids which indicates that the higher value at decreasing percentage was for the water due to a higher heat dissipation. However, the highest value of percentage decreased in temperature gradient was equal to $73 \%$ by using water as working fluid and heat pipe diameter of $22 \mathrm{~mm}$ comparing without those of using heat pipe at the longest condenser length as a result of higher heat dissipation.

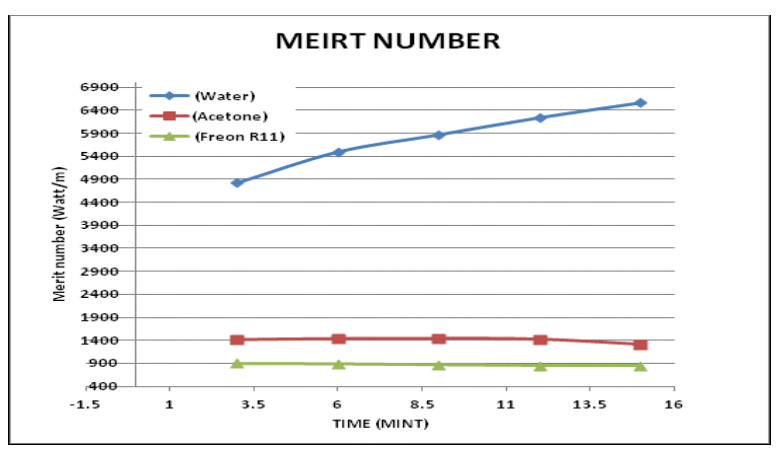

Figure 7: Merit number of three the different working fluids

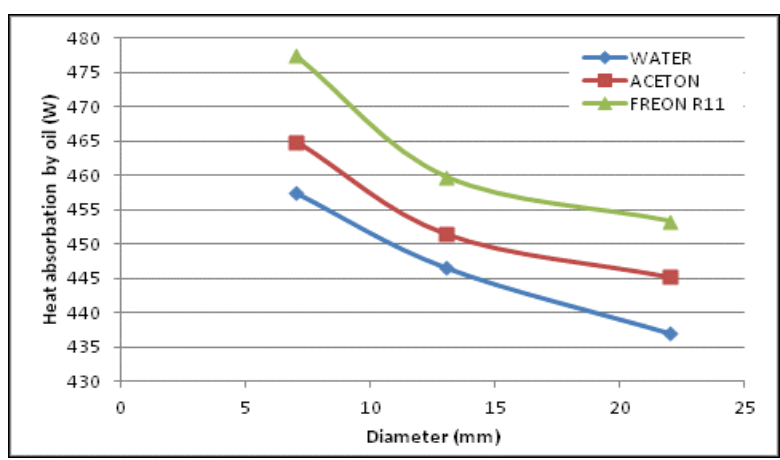

Figure 8: The heat absorbs by oil for different heat pipe diameters and different working fluids at temperature max.

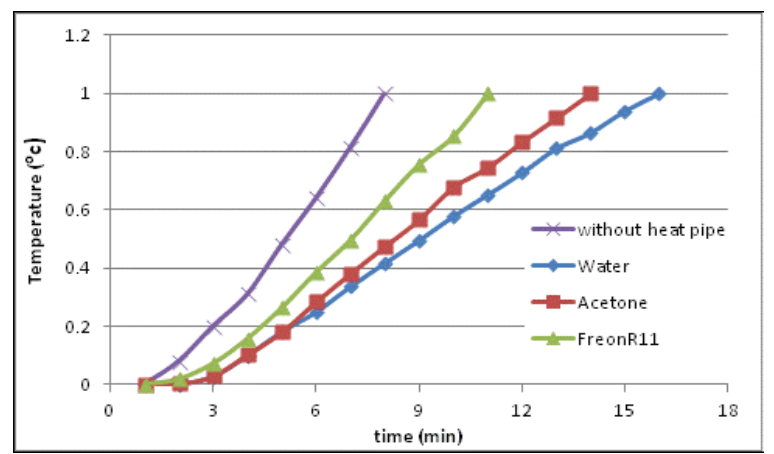

Figure 9: Dimensionless comparison to experimental result for three different working fluid.

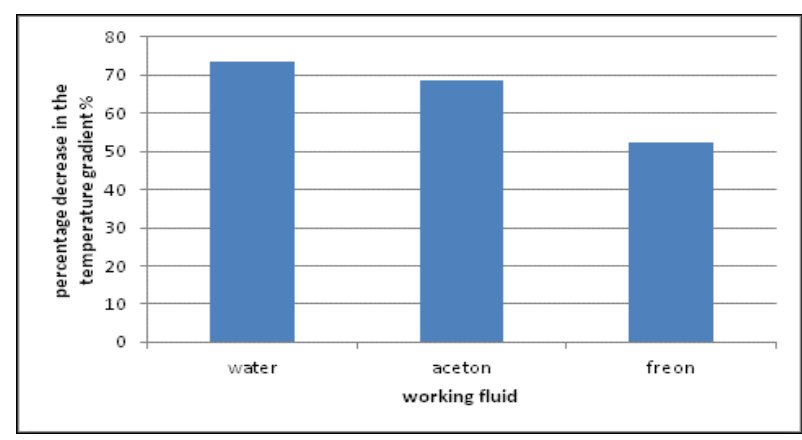

Figure 10: Percentage decreased in the temperature gradient for different working fluid for the heat

\section{Conclusions} pipe diameter of $22 \mathrm{~mm}$.

In this paper, an experiment to assess the performance of a thermosyphon using different diameter and different working fluid were conducted. Three thermosyphon were designed and built with different outer diameters which were 22,13 , and $7 \mathrm{~mm}$. During each test, the thermosyphon was filled with $50 \%$ of examined working fluids which were Freon R11, acetone and water. The study concludes that:

1. The temperature curves were wobbling at low temperature on the thermosyphon.

2. The calculated Merit number of various working fluids such as water, acetone and Freon $\mathrm{R} 11$ at a range of operating temperature between $20{ }^{\circ} \mathrm{C}$ to $80{ }^{\circ} \mathrm{C}$ shows that water had a higher value.

3. The results showed that the water working fluid gave the higher value of heat dissipation than those of Freon R11 and acetone.

4. The decreased temperature gradient for water, acetone and Freon R11 was equal to $73.53 \%$, $68.53 \%$ and $52.35 \%$ respectively.

5. The heat dissipation was increased when the diameter of the thermosyphon increased.

6. The compound effect of different diameters and working fluids showed highest heat dissipation at larger diameter and water working fluid.

\section{References.}


[1] D. Japikse, "Advances in thermosyphon technology," Adv. Heat Transfer, 9: 1-111, 1973.

[2] A. Faghri, "Heat Pipe Science and Technology," Taylor and Francis, USA. ISBN: 1560323833, 1995.

[3] M. Mozumder, A. Chowdhury, "Performance of Heat Pipe for Different Working Fluids and Fill Ratios," Journal of Mechanical Engineering, Vol. ME 41, No. 2, December 2010

[4] M. Kannan, R. Senthil, R. Baskaran and B. Deepanraj, "An experimental study on heat transport capability of a two phase thermosyphon charged with different working fluids," Am. J. Appl. Sci. 11, 584, 2014.

[5] A. Naresh, "Experimental investigations of heat transfer from an internally finned two phase closed thermosyphon," Applied Thermal Engineering 112, 1658-1666, 2017.

[6] E. Gedik, "Experimental investigation of the thermal performance of a two-phase closed thermosyphon at different operating conditions," Energy and Buildings 127, 1096-1107, 2016.

[7] J. Hussam and J.R. Anthony, "Experimental Investigation of Small Diameter Two-Phase Closed Thermosyphons Charged with Water, FC-84, FC-77 \& FC-3283," Journal of Mechanical Engineering, Vol SI 4(5), 144-152, 2017.

[8] T.C. Alejandro Roberto, "Simulation of a distribution transformer," WSEAS TRANSACTIONS on FLUID MECHANICS, Issue 3, Volume 7, July 2012.

[9] N.A. Fadas "Thermal Performance of Thermosyphon Heat Pip Charged with Binary Mixture," Inernational jornal of science, engineering and technology research, 2015. 